\title{
WHAT'S IN YOUR WALLET? \\ ONE WAY TO TRANSFORM RELUCTANT STUDENTS INTO HISTORIANS
}

\author{
Matthew Ridenour \\ Minnehaha Academy (MN)
}

It is the beginning of yet another school year, and I am again confronted by this solemn truth: Not all of my students like history. I know this is hard to believe, considering how compelling the material can be (not to mention how wonderfully engaging history teachers are by nature). Nonetheless, I urge you to set aside your disbelief and hear me out.

In my experience as an educator, students will provide several explanations for their lack of excitement about history. Chief among them is the ever-confounding statement, "I'm not sure that it has anything to do with me." I would be remiss if I did not also mention my personal favorite, "I don't like words" (a profession recently made by a student with an unabashed calculator fetish). Regardless of the reason, these students present a particular challenge for the history teacher; they require a plan of action that subverts their reluctance or apathy and transforms them into lovers of the process of history (for it seems that the content of history might not be alluring enough).

Some students don't need this sort of prodding - they find topics such as the Aroostook War and the subsequent Webster-Ashburton Treaty inherently interesting. However, those who dare to question the importance of such obscure historical events necessitate a different approach from their history teachers. To hook such students, we need to invite them into the fold by demonstrating the complex, inquiry-laden, inductive, scientific processes that make history intelligible in the first place. Otherwise stated, we need to make them historians, with the hope that the process of deciphering history will engage even the most reluctant and apathetic learners.

\section{Historiography Standards and Methodology}

Ernst Breisach argues in his seminal work Historiography: Ancient, Medieval \& Modern that the twenty-first century has brought with it a necessity for historians to "come to terms with the role of creative imagination in historiography." Furthermore, Breisach emphasizes that this should be a reason for rejoicing, insofar as "[historians] once more are called upon to perform the key role of interpretation" as opposed to the secondary role of merely translating the past. ${ }^{1}$

John Lewis Gaddis supports this return to interpretive historiography. While he reminds all would-be historians that "we're obliged to tie our narrative as closely as

${ }^{1}$ Ernst Breisach, Historiography: Ancient, Medieval \& Modern (Chicago: University of Chicago Press, 1994), 410. 
possible to the evidence that has survived," Gaddis still welcomes the use of inductive calculations and certain types of generalizations (what he calls "microgeneralization" or "particular generalization") to produce historical narratives. This sort of calculated creativity is at the heart of acceptable standards in modern historiography.

Additionally, George Iggers notes that today "a new conceptual and methodological approach to history is called for that sees history no longer as a unified process, a grand narrative ... but as a multifaceted flow with many individual centers." Otherwise stated, "Stories are what matter now."

As Breisach, Gaddis, and Iggers all agree, we are in need of a philosophy of historiography that views creative interpretation, story-making, and the testing of hypothesis (through inductive methods) as both appropriate and acceptable. The exercise that follows is designed to cultivate that perspective.

\section{The Set-Up}

I prefer to employ this exercise on the first day of my AP U.S. history course, insofar as I assume that my students represent a typical cross-section of high schoolers, each of whom falls within the predictable spectrum of interest in history. These include history fanatics, reluctant historians, and apathetic students (whom I prefer to simply see as possessing a latent, yet-undiscovered passion for all things history). If I am correct, then a large portion of the class might benefit from the experience.

To begin, you will need a set of identical wallets-usually distributed at a ratio of one wallet for every 3-4 students. Each wallet should have, within its folds, identical sets of documents (meaning that the contents are precisely the same from wallet to wallet, right down to the minutest detail). While a teacher might prefer to choose their own "artifacts" for the activity, I prefer to incorporate the following:

- Approximately $\$ 20$ in U.S. currency ${ }^{5}$

- An ATM withdrawal statement for the aforementioned currency, complete with the account's available balance

- A used ticket to a local sporting event

- A train or bus pass

${ }^{2}$ John Lewis Gaddis, The Landscape of History (Oxford: Oxford University Pres, 2002), 107.

${ }^{3}$ One might also call this "microhistory," which abandons the pursuit of a grand, macro-level historical narrative out of preference for seeking to test historiographic hypotheses in the context of smaller units of research through inductive methods.

${ }^{4}$ Georg G. Iggers, Historiography in the Twentieth Century from Scientific Objectivity to the Postmodern Challenge (Hanover, NH: Wesleyan University Press, 1997), 103.

${ }^{5}$ I use "play money" from popular board games one might have at home. 
- Miscellaneous business cards for local goods and services

- A single photograph of individuals unrecognizable to the students

- A post-it note containing unisex names and phone numbers

Insofar as the exercise requires piecing together multiple sets of the artifacts, making photocopies is absolutely acceptable and does not compromise the authenticity of the experience for students. I have stockpiled copies of used tickets for our local Major League Baseball team over the years, as well as solicited business cards from local merchants. I have used my own checking account for the ATM withdrawal and, after whiting-out my name and account number, made photocopies to distribute in the wallets.

While the content needs to be consistent (from wallet to wallet) in order to be utilized effectively, my suggestions should merely serve as a starting point. What you include might change based on location, context, and availability of resources.

\section{Instructions}

Divide the class into groups of three or four and provide each group with a wallet. Offer no other front-loading information beyond this brief explanation, which I have scripted for the sake of consistency from year to year, although you may change it to suit your personality, or that of your class:

"Before we study history in textbooks, someone has to write it. Someone has to do the work of discovering and interpreting artifacts and documents related to a particular event or person in order to piece together a coherent narrative for the rest of us. This is called 'historiography,' which is the art of the historian. Some of you like history because of the people and stories. Some of you will come to like history because of the process behind those two things. Today we are going to explore that process.

"Each group has been given a wallet to explore. Each wallet and the contents are identical. For the next fifteen to twenty minutes, you have one simple task: Explore the wallet. Use a scratch sheet of paper to write down as many conclusive statements about the owner of the wallet as you feel comfortable. Only write down conclusions on which the group agrees. You may begin."

While students are exploring the wallets, I eavesdrop on their conversations in order to prepare for the upcoming debriefing session, keeping an "ear out" for student statements that will serve as the fodder for a teachable moment or two.

\section{Processing and Debriefing}

After the students have had sufficient time to investigate, explore, discover, and discuss the contents of their wallet (which I believe is approximately 15-20 minute), the 
most critical component of the exercise will begin - processing and debriefing. It is at this point that reluctant and apathetic learners might find something about the complex, inquiry-laden, inductive, scientific processes of historiography to engage them. With that said, the following questions are those that I use in the hope of facilitating said engagement (reporting back is typically done orally):

- Was there anything about the contents of the wallet that led you to a conclusive statement about its owner?

- Describe the processes that you needed to employ in order to draw up those conclusive statements. (Descriptive words such as synthesizing, comparing, contrasting, hypothesizing, and storytelling are common.)

- What artifacts did you think were most directly related to the owner of the wallet, and therefore most helpful in drawing direct conclusions about that individual (primary sources)?

- Are there any "conclusive statements" about the owner of the wallet that you now wish to retract, in light of our further exploration of these topics?

- What is the relationship between context and content, when it comes to historiography?

- How do beliefs, assumptions, and previous experiences color our conclusions?

- In what ways can this exercise inform the way you read history?

- In what ways does this exercise influence your appreciation for the art of the historian?

- In light of this experience, is there anything that we need in our classroom in order to be better students of history? (This could be an object, an attitude, or even a description of the classroom atmosphere.)

\section{To Conclude the Exercise}

As many of us already know, experiences like this and the information gleaned from subsequent processing sessions often are forgotten by students. Even the best lessons are subject to the cognitive decay that results from time. Therefore, I prefer to conclude this exercise (which, again, is the first thing my students do in a school year) by asking them to compile and combine their learnings in order to draft a compact we call "The Task of the Historian." This document becomes an agreement-a scholarly promise to one another that will guide and direct our investigation of history during our class time together. I ask my students to limit their list to five items, although you may choose to shorten or lengthen the list to suit the ethos of your classroom. Below are some examples taken from a previous compact created by my students: 
1. Historians use multiple reliable sources to make arguments and draw conclusions. We will do the same.

2. Historians listen carefully (not just to people, but to the documents that act as living, breathing connections to the past). We will do the same.

3. Historians are mindful of how their personal beliefs, assumptions, and experiences color their historical lens. We will do the same.

4. Historians respectfully question the conclusions of others when they believe there is reason to do so. We will do the same.

5. Sometimes historians love history because it is interesting, and sometimes because the process is fun. We will honor both in our classroom.

\section{Student Feedback}

What follows is feedback provided by my students after experiencing the wallet activity on the first day in AP United States History. Students were 16-17 years of age at the time (juniors in high school). All feedback is in response to the question, "In what ways can this exercise inform the way you read history?"

- "It has helped me to realize that history goes beyond easily observable facts. There is a story to accompany those facts."

- "As a historian, information must be read with context. Without it, many different conclusions could be taken from the same content."

- "One needs to compare and contrast multiple explanations of the same event in order to understand it."

- "This exercise demonstrated the way my past experiences, cultural assumptions, and biases affect the way I see history and make judgments."

- "This exercise illustrates the necessity of a certain attitude of awareness that must be carried while reading history."

- "I realize that I need to be more careful about developing and testing historical hypotheses."

\section{Potential Adjustments for the College Classroom}

While this exercise is presented here for use in the high school classroom, certain adjustments could be made for use in a college setting. Since many institutions require college students to enroll in a survey course in U.S. history (and some of those students would not enroll unless forced to do so), the necessity of drawing in reluctant learners is just as imperative as in high school. In order to do so, I would encourage college teachers to consider replacing the contents of the wallet with institution-specific artifacts such as receipts to the college bookstore, a dining center card, and even a mock dorm room key. This would allow students to contextualize their exploration of the wallet in 
a setting that is rife in familiar assumptions, bias, and stereotypes. This adjustment should make for the type of conversation that would interest a college student. It also would allow students to engage in the complex, inquiry-laden, inductive, and scientific processes so essential to historiography.

An additional change for the college classroom might come by way of abandoning the notion of a compact in favor of assigning a paper. For example, in an American history survey course, one might begin by assigning students the task of collecting a sample of primary sources on the American Revolution and conducting an exploration of them using the same inductive-processes modeled during the wallet exercise. Each student's conclusions then could be compiled in a paper and compared against those of other historians. In my view, this sort of assignment could help cultivate an atmosphere of great ownership over one's study of history.

\section{Conclusion}

After engaging students with this exercise for several years, the long-term results are worth noting. During a recent activity in which students were occupied with another task of investigative narrative-making similar to the wallet exercise (this time centered on the precarious economic circumstances of the 1920s), one formerly apathetic student shouted aloud while referencing of the commitments outlined in our compact, "This makes me love history!" For this one student, an infatuation with the creative and inductive processes of historiography overcame a lack of initial interest in the content. This example is hardly the exception. As a rule, once I invite students to employ such a different approach to history, the atmosphere of the classroom changes-every historical event is a mystery worthy of exploration, every document is a piece of evidence worth exposing, and everyone has a story to investigate and interpret.

With that said, it is true that students tend to forget a skill if it is not consistently practiced. Therefore, I make a point to include an activity in each of our units that reinforces our classroom compact and revisits the aforementioned philosophy of historiography. Additionally, our exploration of primary source documents is guided by those very same principles. Needless to say, the wallet exercise transforms my classroom each fall. I hope that it can do the same for yours as well. ${ }^{6}$

${ }^{6}$ For more information on this exercise, see http://staticl.squarespace.com/static/52477a0ae4b031f96a 665059/t/55dc8502e4b0e21ade3f9e43/1440515330320/Wallet+Presentation.pdf. 